\title{
LIABILITY OF SERVICE PROVIDERS FOR COMMENTS MADE IN THEIR WEBSITES; The rights of freedom of speech and information against the right to honor in Spain in light of the Judgment of the European Court of Human Rights of October 10, 2013 in the case Delfi v. Estonia
}

Ramón Herrera de las Heras Profesor Titular de Derecho Civil Universidad de Almería Email: lasheras@ual.es

\begin{abstract}
This work aims to address, in a practical way, the issue concerning the protection of the right to honor in social networks and websites through the European and Spanish case-law. This is an analysis of the content of such a right, the limits on the rights to freedom of information and speech, as well as regulatory changes needed to adjust the current legislation.
\end{abstract}

KEYWORDS: Right to honor, freedom of speech and information, web pages, service providers, civil liability. 


\section{INTRODUCTION}

With the advent of the internet in European homes in the early 90's, and more recently, with the emergence and rise of social networks, the spread of messages and opinions through the net has undergone a major transformation. What it was needed to be printed before by a means of communication -usually a newspaper or in any other format -e.g. brochures-, now, it can be disseminated instantly and become viral in just a few minutes by reaching potentially millions of users. The advantages in the field of knowledge, information and even freedom of speech are evident, but we can not ignore the fact that it has also generated a number of problems which are very difficult to control. For instance, the spread of messages to support terrorists; the harassment, especially to minors and public persons; or the spreading of rumors and false news from the anonymity. In this regard, the comedian Dieudonné tweeted recently in France "Je me sens Charlie Coulibaly" -I feel Charlie Coulibaly- in defense of the anti-Semitic expressions of the latter. In Spain, the judicial authorities have already taken both criminal and civil actions against these types of messages. In fact, the National Court sentenced a young woman to one year in prison and seven of disqualification for offensive tweets against some members of the government such as: "I pledge to have the face of whom fires a shot to Rajoy and De Guindos' head tattooed". As for civil proceedings, the judgment of the trial court No. 5 in Pamplona of October 15, 2012 is known for being one of the first related ones issued in our country. In this case, a municipal councilor of Pamplona was sentenced to delete the tweets related to Uxue Barcos from March 18, 2011, together with the corresponding compensation, for breaking the right to honor of the latter.

This is why we understand that this subject, the spread of messages through websites or social networks in which citizens' right to honor may be defamed or violated, generates some legal issues. We believe this quandary should be analyzed in order to find any possible legislative amendments to adapt national and European regulations to a reality very different to that existing at the time of the approval of the regulations, which even today remain in force. We must recognize that most of the EU member states have not promptly adapted their legislation to these changes, not even the EU itself. 
It is true that some movements by legislators who are in line to establish specific rules on the matter are currently occurring, but they have not seen the light yet. For instance, in Spain, the Congress of Deputies approved on March 24, 2015 the Report of the Subcommittee of Study on Social Networks ${ }^{1}$ which makes the proposal of adjustment of the traditional protection of honor by modifying two laws which, according to the cited report, have become obsolete: The Organic Law 1/1982, of May 5 on civil protection of the right to honor, personal and family privacy and reputation; and the General Law 7/2010, of March 31 on Audiovisual Communication.

But having an outdated legislation in this area, as noted before, it is the case-law that progresses in the protection of those who are harmed in their right on this matter. In fact, the Judgment of the European Court of Human Rights of October 10, 2013 in the case Delfi v. Estonia has been an important milestone which will be analyzed in more detail in this paper.

\section{FREEDOM OF INFORMATION AND SPEECH V. RIGHT TO HONOR.}

The Declaration of Human Rights of 1789 states in section 11 that "The free communication of ideas and of opinions is one of the most precious rights of man. Any citizen may therefore speak, write and publish freely, except what is tantamount to the abuse of this liberty in the cases determined by Law". This precept has been reflected in the Spanish Constitution, whose section 20.1 recognizes and protects the right to freely express and disseminate thoughts, ideas and opinions by freedom of speech and freedom of information. As it is known, they are two close but not similar rights, since, as pointed out by the Supreme Court Judgment of February 18, 2013, the right to information refers to the communication of facts which are likely to be contrasted with objective data, whereas freedom of speech includes a broader field. It includes opinions,

\footnotetext{
${ }^{1}$ Published in the Official Bulletin of the Parliament No. 643 of April 9, 2015.
} 
which involves a far wider scope, as it is not simply the communication of facts, but the issue of personal and subjective judgments, beliefs, thoughts and opinions ${ }^{2}$.

But as the Spanish Constitution enshrines these rights, the fourth paragraph of the said section 20 provides that "These freedoms are limited by the respect for the rights recognized in this Part, by the legal provisions implementing it, and especially by the right to honor (...)". This last fundamental right is defined, following the classic Italian doctrine, by the Supreme Court, as "the personal dignity reflected in the consideration of others." ${ }^{3}$ Our Constitution includes it in section 18.4, which states that "The law shall restrict the use of data processing in order to guarantee the honor and the personal and family privacy of citizens as well as the full exercise of their rights." We can thus understand, without fear of contradiction, that the limitation of abuse that may occur in social networks and the internet is protected by the Spanish Constitution. What it is complex is definitely to establish the procedure by which to do it.

It is important to note here that the Spanish Constitution speaks clearly about limits, although the case-law has established a system of weighting when the collision of two fundamental rights occurs. In such case, prevalence is given to the rights of freedom of speech and information against the right to honor ${ }^{4}$. Therefore, as the Constitutional Court points out, that special preponderant protection "is subject to certain immanent and external limits which this Court has been refining progressively. Among the immanent limits there are the requirements for accuracy and general interest or public relevance of the information; in the absence of the above two requirements, the Constitutional support to the freedom of information prevails." consistent the case-law doctrine by which, in the frequent collision between the right to honor and freedom of information and speech, all of them of constitutional proclamation, two essential requirements need to concur so that the prevalence of the freedom of speech or information over the right to protection of honor can be declared: 1) that the information provided is about facts of general interest, with political, social

\footnotetext{
${ }^{2}$ On the content of freedom of expression, it is very interesting the work of I. Serrano Maillo, "El derecho a la libertad de expresión en la jurisprudencia del Tribunal Europeo de Derechos Humanos: Dos casos españoles", in Teoría y realidad constitucional, $\mathrm{n}^{\circ} 28,2011$

${ }^{3}$ Judgment of the Supreme Court of November 4, 1986.

${ }^{4}$ Unlawful interference in the right to honor is set out in Article 7.7 of Law 1/1982 which states that "the attribution of facts or the expression of value judgments through actions or expressions in any way impair the dignity of another person, undermining its reputation or attacking their own estimate " will have such consideration.

${ }^{5}$ Judgment of the Constitutional Court of February 24, 2012.
} 
or economic significance; and 2) that the expressed information is truthful, when the duty to verify its accuracy or contrast has been observed or fulfilled. If the information provided is not true, or the contents are not of general interest, we would face with a clear unlawful interference with the right to honor of the harmed person.

But, as stated before, it is not, in my opinion, a matter of strictly prevalence, but of limits. The constitutional preponderance techniques value the circumstances of each case, the intensity and significance of each right, in order to develop a rule that gives priority to one right over another one and helps solve the case through its subsumption in that rule. ${ }^{6}$ I insist that such weighting is not as such, but the content of freedom of speech and information must be evaluated in each case. If someone insults for no reason, and with no relation to the case, we can conclude that this phrase does not fall within the content of the rights of information and speech. Therefore, we will not have to weigh, but to establish the content of those rights for each case.

Nonetheless, there is a fundamental right that protects the right to information and speech, but that right only goes so far as to avoid those untruthful expressions, in some cases, and insulting utterances, in others. ${ }^{7}$ Calling someone e.g. a thief, being this untruthful, does not mean that the right to honor in a supposed weighting prevails over the right to information. It is purely and simply that this untruthful expression is not a part of the right to information - as it does not meet the above mentioned requirements). But that right ends when someone's right to honor is violated. ${ }^{8}$ The European Court of Human Rights (ECHR) has recently pronounced in this sense in its judgment of June 12, 2014 in the Case Couderc Tt Hachette Filipacchi Associés v. France, where it states that "the exercise of freedom of speech implies duties and responsibilities, which also serve to the media, even when it concerns matters of great public interest. These duties

\footnotetext{
${ }^{6}$ F. J. Echarri Casi, .F.J.: ”Derecho al honor «versus» libertad de expresión e información. A propósito del juicio de ponderación”, in Diario La Ley, n. 8096, 2013.
}

\footnotetext{
${ }^{7}$ In this regard we should point out that the resolution 1165 of the Assembly Plenary of the Council of Europe on the right to respect for private life adopted on June 26, 1998 states that "These rights are neither absolute nor hierarchy among them, but they are of equal value."

${ }^{8}$ Although there are many, if not most, authors who keep talking about preponderance. Eg, BUADES FELIU states that "the protection of the right to honor must prevail over the freedom of expression wheb outrageous or offensive phrases and expressions are used, without reference to the ideas and opinions that are exposed and are unnecessary, since the system does not recognize the right to insult". J. Buades Feliu: "Algunas consideraciones de actualidad sobre el derecho al honor, la libertad de expresión y de información”, in Diario La Ley, N. 8318, 2014.
} 
and responsibilities can be particularly important when there is a risk of harming the reputation of a person cited by his or her name and harming the rights of others."9

In line with this argument, the importance of differentiating between false and not verified news or a simple mistake occurred as part of a journalistic investigation that meets the minimum professional standards should be noted. I.e., if a website does not cite any source nor has shown the diligence to which every journalist is obliged, it may also be considered a case of negligence. In fact, the deontological code of Journalists of Spain states in section 13 that "The foundations of the information to be disseminated must be diligently laid, which means that a journalist must contrast the sources and he/she must give a person affected an opportunity to tell his/her own version of the facts." If the alleged information had not been verified, nor the involved person had been contacted, the website would be held liable for such negligence. As the Constitutional Court states, "truthfulness should be understood as the result of the reasonable diligence by the informant to contrast the news according to professional guidelines adjusting to the circumstances of the case, even when the information can eventually be refuted or not be confirmed". ${ }^{10}$ In this case, given that it is freedom of information, in accordance with the recent judgment of the Constitutional Court of December 19, 2013, "the truthfulness, understood as diligence in ascertaining the facts, determines the legitimacy of the right to information".

In the same vein, the Constitutional Court has stated that "the duty of diligence in verifying the accuracy of the information is not satisfied by merely referring to unspecified sources, which, under no circumstances, exempts the author of the information from the compliance with that duty. The reference to such sources, whose origin is not identified, must be understood, initially, as insufficient for the purpose of considering the diligence of the informant as fulfilled, which, certainly does not mean in any way that the informant is obliged to disclose his sources of knowledge, but only to prove that he has made something more than despising the truthfulness or falseness of that information". 11

\footnotetext{
9 This is also included in Section 10 of the Convention for the Protection of Human Rights and Fundamental Freedoms.

${ }^{10}$ Judgment of the Constitutional Court of January 26, 2009.

${ }^{11}$ Judgment of the Constitutional Court of January 16, 1996.
} 
Along the same line, the Constitutional Court has pronounced in its judgment of October 25, 1999, in which it states that "news must be diligently verified and supported by objective facts in order to have constitutional protection".

We should point out that the Constitutional Court has denied such protection under the framework of the freedom of information to those who, "by evading everyone's right to receive truthful information, transmit as true facts, either mere rumors deprived of any verification, or either mere inventions or insinuations, without verifying its accuracy through the appropriate findings of a professional diligent". ${ }^{12}$

A singular case, but perhaps one of the most common ones, is that related to people of public relevance and, especially, politicians, since they are subject to a very close scrutiny and as, on the other hand, it must be. These people have to assume that being temporarily engaged in public life implies receiving criticism, sometimes excessively, on their political work. But this right to criticism and the right to freedom of information and speech, under no circumstances legitimize the insinuations and insults or the publication of false and absolutely untruthful news. Indeed, in many cases these insinuations are made without information on specific elements which such insinuations are based on. This implies that the person concerned can not defend him or herself against such insinuations by proving the untruthfulness of such information, but he or she is disqualified and this is exactly a declaration of value judgments through expressions which have damaged the dignity of the claimant and have undermined his or her reputation and attacked his or her own estimation. This fact agrees precisely with the consideration of unlawful interference with the right to honor, as defined by the Organic Law 1/1982, of May 5 on civil protection of the right to honor, personal and family privacy and reputation, in section 7.7, amended by Organic Law 10/1995, of November 23, of the Criminal $\operatorname{Code}^{13}$. We can also conclude that the insidious insinuations represent a violation of the right to honor because they can not exceed the intended informative purpose by giving an insulting, degrading and disproportionate nature, since, as the Constitutional Court has reiterated, the Spanish Constitution does not recognize the hypothetical right to insult. ${ }^{14}$

\footnotetext{
12 Judgment of the Constitutional Court of November 16, 1996.

${ }^{13}$ Judgment of the Supreme Court of September 24, 2009.

${ }^{14}$ Among many others, the judgments of the Constitutional Court of April 14, 2008 or the judgments of the Supreme Court of February 18, 2009 and June 17, 2009.
} 

OF MESSAGES IN SOCIAL NETWORKS

The European Union started regulating this issue by Directive 2000/31/EC of the European Parliament and of the Council of 8 June 2000 on certain legal aspects of information society services, in particular electronic commerce, in the Internal Market. Such Directive establishes in its section 4 the liability of intermediary service providers which, as TEJEDOR MUÑOZ states, creates a system of waivers of liability of intermediaries with exceptions. ${ }^{15}$ Section 14 provides, basically, that the service providers shall not be liable for damages caused to third parties, provided that two conditions are met: First, when the provider does not have "actual knowledge of illegal activity or information"; and, second, that he or she "acts expeditiously to remove or to disable access to the information." The problem posed by the contents of the Directive is that it does not state what is meant by "actual knowledge" or how long must it take for the data to be removed or prevented from its access once it is known that the information is unlawful. ${ }^{16}$ It has been the case-law which has established some general criteria to bridge this gap, as we will discuss later.

The abovementioned Directive was transposed in Spain by the Law of Information Society Services of Spain (LSSICE), whose special relevance lies both in the accountability system and in terms of the information and transparency of its contents. Thus, their legal terms should contain information regarding how the opinions of users will be posted, if some kind of prior censorship or restraint will be exercised, and which criteria would be used to protect the rights of third parties. So, it is the service providers that are obliged to articulate a system to prevent the publication of messages that insult or attribute criminal facts to persons or entities that may, in some way, violate their fundamental right to honor. Undoubtedly, a basic element is the need to identify the users who will be making the comments, as they should be the ones responsible for them. Otherwise, it will be the website that will be held responsible for the unlawful interference that may occur. This has been endorsed by the Judgment of the European

\footnotetext{
${ }^{15}$ L. Tejedor Muñoz: "Hosting o administradores de servicios de páginas web e intromisión al derecho al honor: La responsabilidad civil en el marco de la sociedad de la información", in Revista Crítica de Derecho Inmobiliario, n. 727, 2011
}

${ }^{16}$ TEJEDOR MUÑOZ, L.: “Hosting o administradores...” op. Cit. 
Court of Human Rights of October 10, 2013 in the case Delfi v. Estonia. It is common to see that in too many websites it is not necessary to register to post a comment, in order to identify, where appropriate, the person who may incur in an action that causes any damage.

It is true that some judgments require that a deadline for the responsible for the websites is given, so that, if the event of existing offensive comments, they can be removed. This communication -which can be made by known means as burofax or email, would imply that, if the website does not remove the existing comments promptly, it will be held coresponsible for them, either because it has not removed the comments since it agrees with the contents expressed therein, or either it has incurred in a clear lack of diligence by not restraining or removing these comments, being aware of them. In my opinion, the removal of those comments, once the offended has informed about them, should not imply the exemption from liability. It should be a way to mitigate such liability, since the damage has been already caused and it is evident that appropriate means to avoid it were not carried out.

The case-law in this case is fairly forceful in condemning those responsible for the websites who lack the means of control or identification. In fact, the Supreme Court judgment of February 10, 2011 agrees with the decision given by the Provincial Court of Madrid of October 30, 2008, section 13, in which the defendants were sentenced by the comments appearing on their website. This was despite the fact that the comments had not been written by them nor had they received any notification about their unlawful content. Nonetheless, with due diligence, they could have been aware of them. As stated in the abovementioned Judgment, "Notwithstanding the above that no decision was preceded which declare the unlawfulness of the content of the statements and the photograph of the website, since it is clear that in the present world of telecommunications, given the ease and speed of data dissemination, the fact of referring the injured person to the previous formal declaration of unlawfulness when the interference with the right to honor is as noticeable as in the present case, would multiply the damage."

We should note that service providers are imposed a duty of care and collaboration. In fact, in the LSSICE, in its section 11, a duty general of information is imposed to any service provider who must provide information concerning their identity and location 
data, as referred to in section 10. This allows having an overview of who the service providers are and how they can be reached so that it is ensured that, in case of conflict, they can be identified. Therefore, the obligation to remove any unlawful content or prejudicial to honor data of a certain person can be met diligently. This would thereby help prevent its spread and its extension in time. This party, as pointed out in the facts, submitted the corresponding request to remove such comments to the address appearing on the website, but no response was received. In this same vein, the Spanish Supreme Court has pronounced in its judgments of February 10, 2011, according to which "the defendant did not observe the minimum diligence required so that the injured could contact him in an easy and direct way in order to interrupt the publication of those oral statements or photographs that could be considered injurious, since he kept on storage an inaccurate home address. The injured was thus prevented to communicate with him in an easy way."

The Supreme Court establishes clearly in the same judgment that "so that the exemption from liability occurs, as stated in section 16 of the LSSICE, three requirements must be met: a) the defamatory information is hosted on the server of an intermediary service provider of the information field; b) such intermediary was not actually aware of the unlawful nature of the stored data, or if so, he or she removed them; c) the author did not generate the data under the direction, authority or control of the intermediary. These conditions are fulfilled in the present case, so the judgment under appeal incurs in the alleged infringement, as the cause for liability exclusion regulated by such provision is not concurrently approved." In this case, the appellant argued that "although he allowed hosting contents on his server - in particular the claimant's messages, opinions and photograph - he did not participate in the selection, design or organization of such information, but he merely provided a mediation service in absolutely neutral terms. So no responsibility for his behavior should be attributed to him.” Such reason, as pointed out before, was dismissed by the Supreme Court.

The Supreme Court has provided a broad interpretation of the $1^{\text {st }}$ paragraph of section 16 of Law 34/2002 (Judgment of December 9, 2009, Appeal No. 914/2006, in addition to the one now indicated), as it unjustifiably reduces the possibilities of obtaining "actual knowledge" of the unlawful nature of the stored contents and extends correspondingly the scope of the exemption regarding the terms of harmonizing legislation, which requires an effective knowledge, but without restricting the suitable 
instruments to reach it. While section 16 of Law 34/2002 allows this favorable interpretation of the Directive as it does not limit the possibility of "other means of actual knowledge that may be established", it should not be neglected that it attributes equal value to the "actual knowledge" as to the one obtained by the service provider from suitable facts or circumstances to make an effective apprehension of the concerned reality possible, even mediately or by logical inferences available to anyone. On this basis, the Provincial Court attributes the same revealing value to the stored or linked contents inasmuch as its unlawful nature is obvious in itself, as it does not depend on data or information which is not available for the intermediary. This Court considers that both the photograph and the expressions used constitute a flagrant interference with the claimant's right to honor, and states that no judgment declaring the unlawfulness of the contents thereof was necessary. That conclusion is consistent with the doctrine expounded, and it leads to the conclusion of the defendant's lack of diligence in fulfilling the burden referred to in part b) of the aforementioned section 16 of Law $34 / 2002$.

In this same sense, the European Court of Human Rights has pronounced in the important Judgment of October 10, 2013 in the case Delfi v. Estonia, which holds a digital communication medium liable for the violation of the right to honor committed by its readers by means of their comments posted about the news, and which the medium publishes concealing the identity of the authors. In this sense, the sentenced should have "taken any action to promptly remove any offensive comment." Thereby, the ECHR states that "although the website removed the comments when he was asked to do it, it did not have the necessary instruments to prevent the publication of insulting comments in an automatic way." This fully endorses the position expressed in this paper which supports the idea that the removal of the comments should not exempt from liability, but it can mitigate it.

Thus, as stated by the ECHR, when the medium allows readers to comment anonymously, it is "reasonable" to hold the editor responsible, since the news portal gets commercial gain from the website, and comments are part of its contents. Definitely, the ECHR has given priority to the right to honor since "it has been proved that the website did not act with due diligence". 
In this same sense and in a very similar case, the judgment of the Provincial Court of Badajoz of September 17, 2010 (280/2010) states that, "just as the defendants could examine the contents of the messages to examine or analyze such suggestions, they had also certainly access to the messages which, far from considering suggestions, contained the defamatory expressions which have led to this procedure. And, if they allowed them being kept posted on the net, when they could have been removed, by themselves (...), they can not be now exempted from liability by arguing, as also made by the Public Prosecutor, that the messages have not been directly made by the defendants, without being essential, otherwise, and within the framework of a civil procedure, such as the present one, to find out the specific persons who submitted the messages." With the same argument, the said judgment continues by stating that "it is understood that the owners of the domain and the website would obviously examine its contents, and in the same way they knew those suggestions and had them at their disposal, they also knew the defamatory contents, or, at least, they had the possibility to know them. So the infringement of the right to honor caused through the website has been committed by those who had the possibility to select the contents of what it was transmitted and disseminated to the users."

\section{MESSAGES WHICH VIOLATE THE RIGHT TO HONOR IN SOCIAL NETWORKS.}

In accordance with the Opinion 5/2009 on online social networking, we can define social network services as "online communication platforms which enable individuals to join or create networks of like-minded users". ${ }^{17}$ According to a study conducted by the Interactive Advertising Bureau (IAB), social networks are used in Spain by over 14 million users, and the most common ones are Facebook, Youtube and Twitter. ${ }^{18}$

In social networks, the issue concerning this paper is different, since in order to make comments it is necessary to be registered and to have an account in which the necessary identification data have been requested. A different matter is how to control beforehand that the data entered by the users are true. This is an issue to be addressed by experts,

\footnotetext{
17 The opinion, approved on June 12, 2009, was prepared by the working group on data protection pursuant to Directive 95/46 / EC, and it is available in the following link: https://portal.uah.es/portal/page/portal/proteccion_datos/repositorio/wp163_es.pdf
}

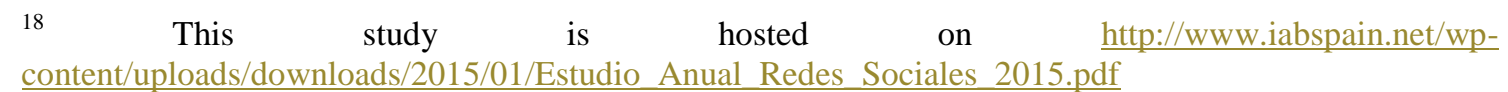


but it should include the possibility of record through the use of an electronic certificate in order to guarantee the accuracy of the data provided by the user. In this sense, the judgment of January 13, 1997 of the Constitutional Court states that "If someone else's writing is published and the author's identity is unknown by the medium, it should be understood that the medium has assumed its content." The Supreme Court has pronounced in the same vein in its judgment of July 19, 2004.

A different matter is whether social networks, especially Twitter and Facebook for being the best known, can be considered as media. I understand that the answer should be negative, among other reasons, because if not, it would imply that these networks should censor tens of thousands of messages per minute, which, apart from being impossible, it would prevent these useful tools from having the sense of immediacy they currently have. It would make more sense to force these social networks to have a more secure user identification system which prevented the use of pseudonyms or the inclusion of false data. If they had this system available, it is obvious that those responsible for the offensive comments could not hide behind the anonymity. The desirability, in a few years, of the use of digital certificates required to create a profile on these social networks is obvious.

With regard to unlawful interference in this field, we must point out the increasing number of court judgments in which the author is sentenced because of $\mathrm{it}^{19}$. No variation regarding the concept of honor is found and we must consider that the publication of expressions or messages which violate this right in social networks must not have a special particularity compared to those issued in any other context, except as regards to the sentence which will be discussed later. Once identified the author of the interference, it must be reprimanded as forcefully as the rest of the authors of any unlawful interference.

\section{REMEDY OF DAMAGE CAUSED BY OFFENSIVE COMMENTS ON SOCIAL NETWORKS OR WEBSITES}

When the courts establish the obligations arising for convicts, apart from the economic ones, they always consider the effect of the information in order to set the proportionate

\footnotetext{
${ }^{19}$ Among others, the following ones: Judgment of the Court of Instruction 4 of Segovia of February 21, 2011; Judgment of the Criminal Court of Vigo of February 15, 2013; Judgment of the Criminal Court of Córdoba of February 7, 2011; Judgment of the court of Pamplona of October 15, 2012.
} 
measures to compensate, as far as possible, the honor which has been damaged. But we find that, in the case of social networks and websites, the effect of their comments, and therefore the damage to the holder of the violated right, is much broader than the one which can be produced by traditional media. Typically, in these cases, the information or comments are shared on social networks virally which has two harmful consequences for rights holders; first, it is be very difficult to delete all comments or images in this regard, as they may be housed in the Timeline of thousands of users or on thousands of different servers. Second, they can reach a very wide spread. In fact, a single retweet or the sharing of comments have an almost unlimited potential reach if we consider the number of followers of those who carried out such actions. Thus, in addition to the economic compensation - we will not discuss this aspect here as it has been dealt with profusely by many authors - the peculiarity of these cases is that the spread of the conviction and the compensation should be carried out in the same social networks or websites. Moreover, the immediate removal of the messages will be obviously required. Thereby, the Court of First Instance of Sevilla No. 22 sentenced a user in its judgment No 235/2014 to publish the judgment in his social network every day for a month, as well as to delete from his Twitter profile the 47 tweets subject of the complaint, and which were considered harmful by the judge. 